\title{
مشكلات تعلم اللغة العربية بمهارة القراءة
}

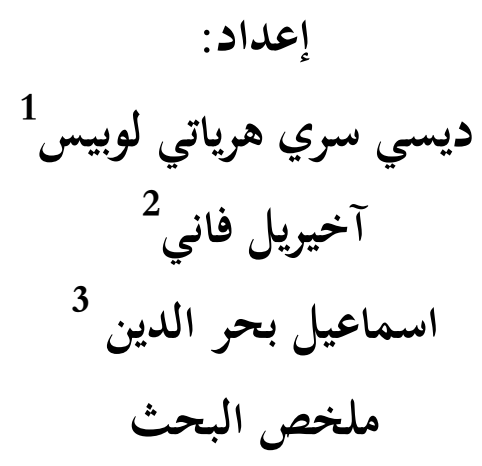

خلفية في هذا البحث هي مشكلة تعلم اللغة العربية بمهارة القراءة كيف تكون تعلم

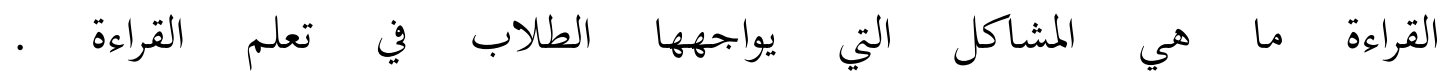
بناء على هذه المشكلات، فغرض سينجز في هذه البحث لمعرفة كيف تكون تعلم القراءة,

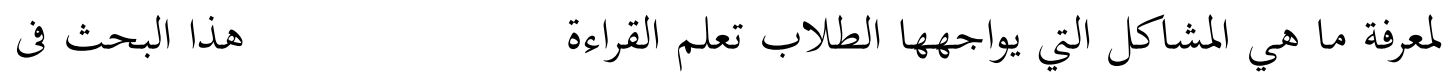
مدرسة المتوسطة الحكومية الأولى بالنسبة لمصدر البيانات هي التلاميذ فصل الثامن ومدرس. اما نوع البحث الذي يصور حول مواقف الالة ليجمع البيانات هي المقابلة والمالاحظة

بعدان يقيم البحث تعرف ان صعوبات التلاميذ في تعلم اللغة العربية كثيرة، يعني يحتاج المدرس التركيذ في تعلم اللغة العربية، العوامل الاسباب توجد صعوبات على التلاميذ فصل الثامن في مدرسة المتوسطة الاسلامية الحكومية الأولى بادانج سيدمبوان هي قليلة

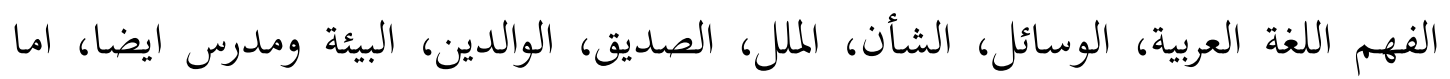

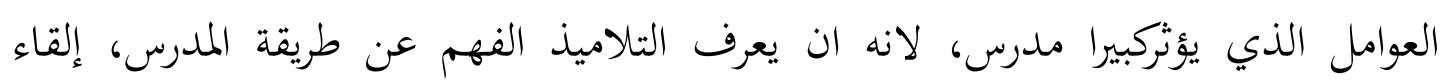
الدرس المناسب بمهارة، التلاميذ يعطى الفذلكةالذي يتعلق المادة الذي يدرس فيها. 


\section{المقدمة}

أصل القراءة تأتي من الكلمة قراءة: قرأ-- يقرأ-- قراءة المعن قرأ, في اللغة مشتق من كلمة من الآية الأولى من نزول القرآن أن سورة العلق, في سياق تعلم اللغة العربية، كما قيل أن القراءة هي المهارة التي ينبغي تحقيقها, ويأتي مع مهارات القراءة، ومن المتوقع أن تكون قادرة تنطق بشكل صحيح الحروف العربية الطلاب، فهم مضمونما يكتب، لأن القراءة هي النشاط الذي ينطوي على الحواس البصر والفكر للقبض على محتويات محتوى النص للقراءة. وهناك عدة أسباب لماذا يجب علينا دائما قراءة, أولا، القراءة هي وسيلةلاكتساب المعرفة,الثاني القراءة هي وسيلة لالداخلي, الثالث القراءة هيواحدة من وسائلالترفيه,الرابع القراءة يمكن أن بحلب الرزق, الخامس القراءة هي النشاط لفهم، تفسير، يتذكر وإعادة كتابة استنادا إلى تحليل من عقولنا.

النظام التجاري المتعدد الأطراف نيجري أنا بدنج سدمبوانغير

المدارس الدينية التي تعلم اللغة العربية باستخدام نظام نظرية الوحده الكل في نظام واحد (أل هذا هوأن اللغة العربية هي أداة الاتصال في مهارات التدريس التي تغطي 4 الحوار (محادثة)، أرشفة ( الهيكل )،قرأة (اقرأ)، والكتابة (الكتابة). قرأة ( اقرأ )هي واحدة من المهارات اللغوية التي ينبغي تحقيقها بالإضافة إلى تدريس مهارات اللغة العربية من الاستماع والتحدث والكتابة، التي هي عملية تحديد وتفسير وتقييم الأفكار فيما يتعلق الوزن الكلي للوعي القارئ.

طلاب النظام التجاري المتعدد الأطراف نيجري ابدنج سدمبوان طلاب الذين لديهم القدرة (القراءة) غير متجانسة. وذلك لأن عدم المساواة في القدرة، 
الخلفية للمدرسة، وعامل آخر. وهكذا، في التدريس للمعلمين وجود مشاكل مختلفة. عندما تعلم القراءة الخفاض الدافع طالب في الصف، عندما المعلم يشرح الكثير من الطلاب الذين لا تولي اهتماما لبعض حتى تتحدث عن نفسها. فمن لأغمم يعتبرون اللغة العربية هي

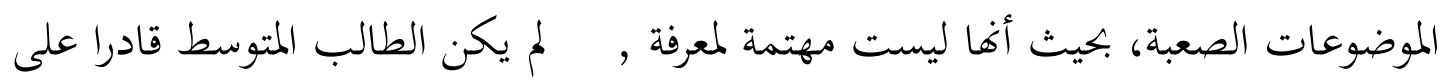
قراءة النص العربي بشكل صحيح بسبب عدم الاعتراف، والقدرة والرغبة في التعلم القراءة باللغة العربية. بحيث اهتمامهم باللغة العربية أقل. النظام التجاري المتعدد الأطراف نيجري البدنج سدمبوان المدارس الدينية يعادل المدرسة الإعدادية أنه بالإضافة إلى تدريس العلوم العامة أيضا تدريس العلوم الدينية، واحدة منها هي اللغة العربية عملية التعلم بين المعلمين والطلاب شهدت العديد من الصعوبات، خاصة في قراءةالتدريس "آه. ولذلك، فإن الكتاب والمهتمين في البحث. مشكلة التعليم اللغة العربية بمهارة القراءة.
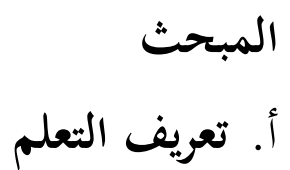

اي: " التعلم هوعبارة عن بحموعة لتحفيق لتعلم الطلاب مع مراعاة الوقائع الدخلي

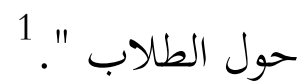

اي: كثيرا ما حددت مع كلمة تعليم تعلم اشتقاقي يأتي من جذر الكلمة 'التعلم' وهوما يعني أن تعليمات أعطيت لتلك التي هي معروفة (الواجب اتباعها) إلى جانب البادئة hlm. 12

${ }^{1}$ Eveline siregar dan Hartini Nara, Teori Belajar dan Pembelajaran (Bogor: Ghalia Indonesia, 2010), 
"بي" ولاحقة "ب" إلى " تعليم 'وهوما يعني العملية، والتصرف أوتعلم حتى يتمكن الطلاب 2

اي: التعلم هومزيج يتضمن عناصر المحتشدة البشرية والمادية والمرافقوالمعدات،

والإجراءات التي تؤثر على بعضها البعض تحقيق أهداف التعلم · 3

اي: بينما في قانون الوطنية الفصل نظام التعلمالمادة الأولى رقم عشرون سنة

ب . . ץ على ما يلي: "التعليم هوعملية تفاعل المتعلمين مع المعلمين ومصادر التعلم في بيئة تعليمية

اي: التعلم هومحاولة مباشرة أومحاولة لتوجيه أنشطة الطلاب نغوالأنشطة في

نفس الوقت، ونشاط التدريس (المعلمون) وأنشطة التعلم (طالب .(عملية التعليم هي

عملية التفاعل بين المعلمين والطلاب والطالبات .عملية التعليم هي الحالة النفسية التي

وجدت على الجوانب النفسية عندما تعليم تأخذ مكان .ولذلك، فإن عملية التعليم

هوالحالة النفسية، يطلب من المعلمين لخصم الفهم النفسي للأجل حل المشاكل

النفسية التي تنشأ في عملية التعلم. 5

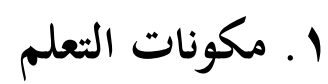

وثمة عنصر هوجزء من الجسم في استراتيجيات التعلم. عملية التعلم والتعلم فيالمدارس

هونظام التفاعل، فهذا يعني ككل والذي يتألف من المكونات التي تتفاعل مع بعضها

${ }^{2}$ Tim Penyusun Departemen Pendidikan Dan Kebudayaan, Kamus Besar Indonesia, (Jakarta: Balai Pustaka, 1991), hlm

${ }^{3}$ Oemar Hamalik, Kurikulum dan Pembelajaran, (Jakarta: Bumi Aksara, 2008), hlm. 57.

${ }^{4}$ Depag, Undang-Undang dan Pemerintahan RI tentang pendidikan, (Jakarta: Dirjen Pendidikan Islam Departemen Agama RI, 2006), hlm, 5.

${ }^{5}$ Tohirin,Psikologi Pembelajaran Pendidikan Agama Islam, (jakarta:PT.Raja Grapindo Persada, 2005), hlm,8-9. 


$$
\begin{aligned}
& \text { البعض. وهكذا نواجه عددا من العناصر يجب أن تكون موجودة. وبدون عنصر لا } \\
& \text { يحدث عملية التربوية بين المعلمين والمتعلمينالمكونات هي: }
\end{aligned}
$$

\section{أ. مكونات الأهداف التعليمية}

توعية الناس وتنمية الشعب الاندونيسي بأسره، أي الناس الذين هم المؤمنين إلى الله، والأخلاق والمعرفة والمهارات، والصحة البدنية والروحية، شخصية قوية ومستقلة

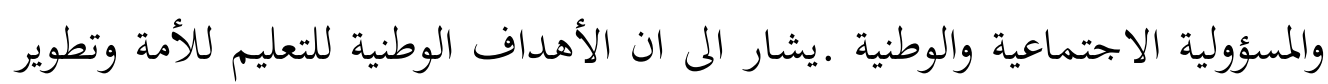

$$
\begin{aligned}
& \text { الشعب الاندونيسي بأسره، ويمكن تفسير مع الخصائص التالية: } \\
& \text { أ. آمنوا واتقوا الله } \\
& \text { ب. الطابع النبيل } \\
& \text { ج. لديهم المعرفة والمهارات }
\end{aligned}
$$

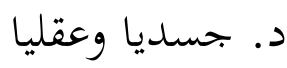

$$
\begin{aligned}
& \text { هـ. شخصية قوية ومستقلة } \\
& \text { و . نخن مسؤولون أمام المجتمع والأمة. } 6 \\
& \text { ب. مكونات المواد التعليمية }
\end{aligned}
$$

مواد الدراسة هي مادة ليتم تسليمها في عملية التعلم .في حين قال سوديرمان أن مادة الدرس هوالشيء الذي يجلب رسالة لأغراض تعليمية .دون تدريس مواد التدريس وعملية التعلم لن تسير بسلاسة ودراسة المواد التي سيتم عرضها على الطلاب بشكل جيد .لذلك، المواد التعليمية يجب أن تكون مستعدة بشكل جيد لتنفيذ التعلم لتحقيق هذا الهدف.

\footnotetext{
${ }^{6}$ Oemar Hamalik, Kurikulum dan Pembelajaran, (Jakarta: Bumi Aksara, 2008), hlm. 45
} 


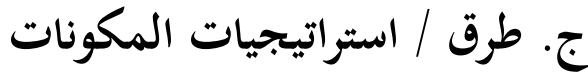

الاستراتيجيات والأساليب هي العنصر الثالث في تطوير المناهج الدراسية .

هذا العنصر هوعنصر له دور دور مهم جدا، لأنه يتعلق بتنفيذ المناهج الدراسية.

\section{Y. العوامل التي تؤثر على نظام التعليم}

كمؤسسة موقف إسلامي نموذجي، المدرسة الثانوية على الرغم من تصنيفها

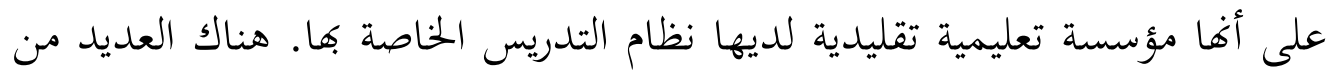

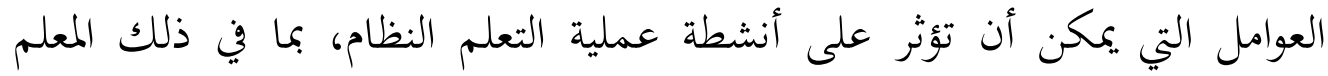

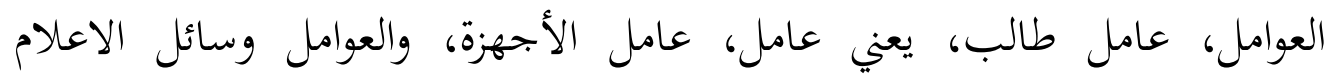
والعوامل البيئية. ويككن تفسير هذه العوامل على النحوالتالي

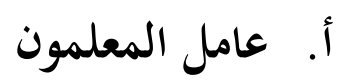

المعلمون هم العناصر الحاسمة كما هوالحال في تنفيذ استراتيجية التعلم. دون المعلمين، ولكن جيد ومثالي استراتيجية، ثم استراتيجية لا يمكن أن تطبق بشكل 7

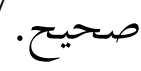

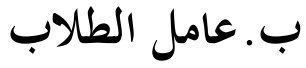

العوامل التي قد تؤثر على الطالب في عملية التعلم هي خلفية الطالب هي

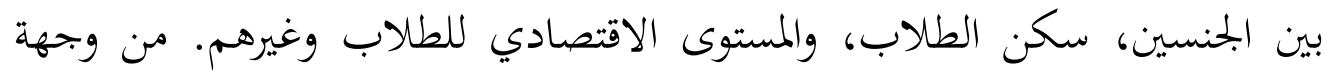

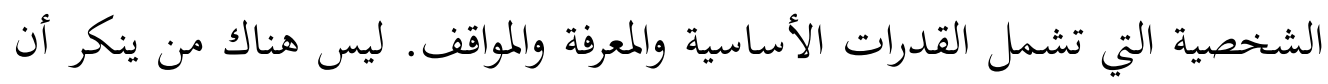

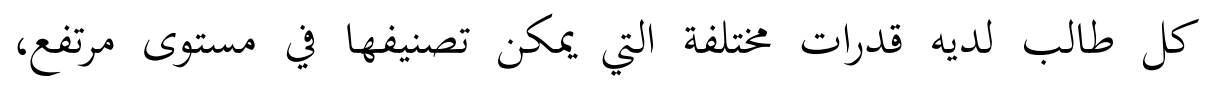

\footnotetext{
${ }^{7}$ Ibid. hlm. 60.
} 
متوسط، ومنخفض. وتتطلب هذه الاختلافات معاملة مختلفة في كل من التنسيب وفي الطلاب بحميع. موقف وأداء الطلاب في الفصول الدراسية هوجانب آخر يمكن أن تؤثر على عملية التعلم. وجدت بعض الأحيان أن يكون الطلاب الناشطين، الذين هم، وليست قليلة كما عثر على الطلاب الذين لديهم الدافع منخفضة في التعلم. الظروف للمعلمين يجب أن يكون لاحظت بشكل صحيح للطلاب الذين

$$
\text { لديهم الدافع للتعلم. }
$$

\section{ج. عناصرالبنية التحتية}

وسائل أي شيء التي تدعم بشكل مباشر على سلاسة عملية التعلم.

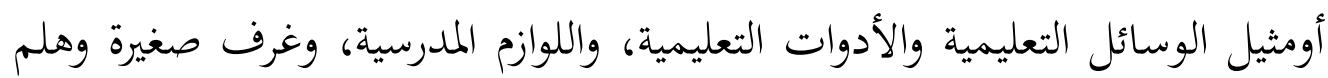
جرا. وهكذا المرافق والبنية التحتية هي المكونات الهامة التي يمكن أن تؤثر على عملية التعلم. وبعبارة أخرى، يمكن أن المرافق والبنية التحتية في عملية التعلم تؤثر على النجاح. وفقا للمبدأ المذكور أعلاه أن وسائل هي واحدة من الأشياء التي هي مهمة لتحقيق أهداف التعلم.

\section{د. ـ عناصرالبيئية}

بشكل عام، والبيئة هي كل ما هوحول الطلاب إما الأشياء أوالأحداث التي تحدث .انطلاقا من البعدين من العوامل البيئية التي يمكن أن تؤثر في عملية التعليم، وهي عامل من تنظيم الصف وعوامل أوظروف الطبقة المناخية. r. مشاكل في تعلم اللغة العربية

في تعليم اللغة العربية وكان شائعا أن نقول أن هناك مشكلة أوقضية. ولكن قبل ينظر إلى مشاكل في السؤال باللغة العربية، وصفت أولا ما هوالمقصود من 
المشاكل. وفقا لمراكز تدريب منتخب معجمي وتطوير لغة تفسر "مشتق إشكاليات

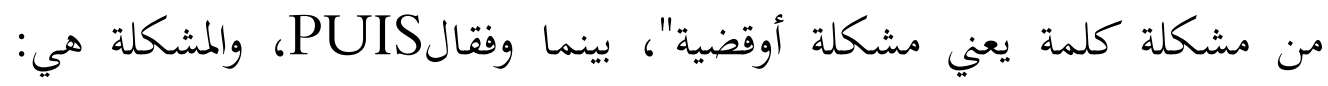

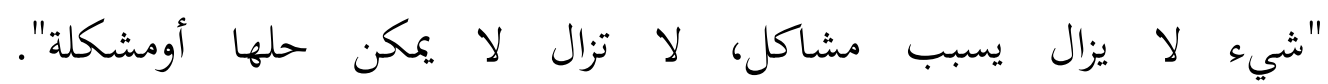
إشكالية أبحث في كان لا يزال يسبب مشاكل، لا تزال لا يمكن حلها أومشكلة. لذلك، فإن المشكلة هي ما يشكل مشكلة لشخص ما لتقديم وتنفيذ شيء ما، وهوفي هذه الحالة مناقشة توفير هذه القضية، وتنفيذ اللغة العربية في الأسرة، وخاصة التعليم في بحال الإعلام، والأساليب، والتقييم.

\section{ب. تعريف القراءة}

وفقال Izzan في التفسير التالي قال إن مهارات القراءة وتعلم القراءة

والهدف بكيث يمكن للطلاب قراءة وفهم ما يقرأون بشكل صحيح .في حين أن

الطريقة التي تقدم درسا في كيفية قراءة، إما للقراءة بصوت عال أوقراءة بصمت .

نأمل، كان الطلاب قادرين على نطق الكلمات والجمل في الصحيحة العربية، على

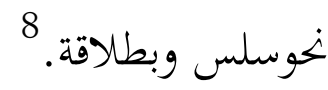

\section{ج . أهداف تعلم القراءة}

وهنا غرضين من مهارات القراءة، أي أغراض العامة والأغراض الخاصة.

$$
\begin{aligned}
& \text { الهدف العام من تعلم القراءة وهي: } \\
& \text { 1. التعرف على المخطوطات اللغة. } \\
& \text { r. تفسير واستخدام المفردات الأجنبية. } \\
& \text { r. فهم المعلومات الواردة صراحة وضمنا. }
\end{aligned}
$$
168.

${ }^{8}$ Syaiful mustofa, strategi pembelajaran bahasa arab inovatif(UIN MALIKI PRESS, 2011), hlm. 164- 


$$
\text { ع . فهم معنى المفاهيمي }
$$

ه. فهم قيمة التواصل حكم صادر بحقه. 7. فهم العلاقة في الجملة، بين الجمل، بين الفقرات. V. تفسير قراءات. تحديد المعلومات الهامة في الخطاب. م. التمييز بين الفكرة الرئيسية والأفكار الداعمة. 9 ه تحديد الأشياء الهامة التي يجب أن تكون موجزة. أما بالنسبة لغرض محدد هوتعلم مهارات القراءة وتنقسم إلى ثلاثة مستويات 1 من اللغة، التي هي في مستوى مبتدئ، متوسط، ومتقدم. التعرف على الرموزلغة حر

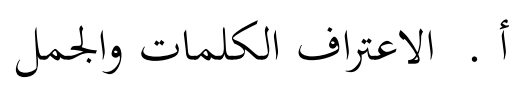
ب. العثور على الأفكار الرئيسية والكلمات الرئيسية ج. رواية محتوى القراءة قصيرة r. المستوى المتوسط أ. إيجاد الفكرة الرئيسية ودعم الأفكار ب. سرد أنواع مختلفة من المحتوى القراءة ب. - م. المتقدم أ. إيجاد الفكرة الرئيسية ودعم الأفكار ب. تفسير محتوى القراءة 


$$
\text { د. د. درد أنقاع مختيم جوهر القراءة }
$$

طريقة القراءة (طريقة القراءة) ويمكن القيام به على النحوالتالي:

I. المباشر تدريس القراءة لهذا الموضوع، يدفع الطلاب الانتباه إلى قراءات.

$$
\text { r. المعلمون قراءة مرة أخرى، ثم اتبع الطلاب معا. }
$$

r. المعلمين بتعيين أحد الطلاب لقراءها في المنعطفات.

ـ. المعلمين تسجيل الكلمات الصعبة على متن الطائرة، ثم المعلم للعثور قال مرادف أوالمعارضين أن الطلاب تمكنوا من اعتقد ان هذا هوالقول، قبل أن يشرح

$$
\text { المعلم المعنى الحقيقي إذا لزم الأمر. }
$$

\section{ع ـاستراتيجيات التعلم القراءة}

مهارات القراءة استراتيجيات التعلم (المهرة آلقراءة)، وتنقسم الم ثلاثة

مستويات، وهي استراتيجية على مستوى مبتدئ، متوسط، ومتقدمة، وهي:

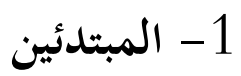

على هذا المستوى "وعادة ما تستخدم في المقام الأول لاستراتيجية خخطط فارغة، الاستراتيجية التي تستخدم لتدريب قدرة الطالب على صب محتويات وهويقرأ في شكل جدول. على سبيل المثال، الطلاب قادرين على التمييز بين

$$
\text { 2- المستو والفعل. }
$$

على هذا المستوى عادة استخدام مؤشر استراتيجية مباراة بطاقات، أي 
استراتيجية تستخدم لتعليم الكلمات أوالحمل مع شريكه .على سبيل المثال،

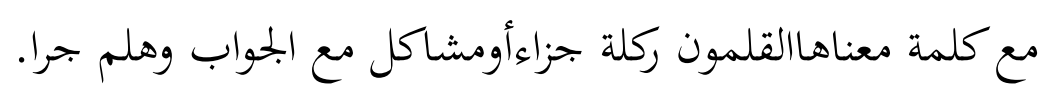

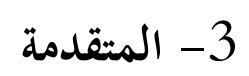

وعلاوة على ذلك لأهواء هذا عادة ما تستخدم في تحليل استراتيجية، وهي الاستراتيجية التي يتم استخدامها لتدريب الطلاب في فهم محتوى القراءة من فاده خلال إيجاد الفكرة الرئيسية /الرئيسية ودعم الأفكار.

\section{هـ ـ ت تقنيات تعلم آلقراءة}

اي: الكفاءة في القراءة يحتوي على جانبين من جوانب التفاهم .أولا، تغيير

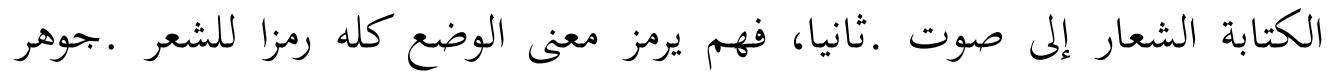

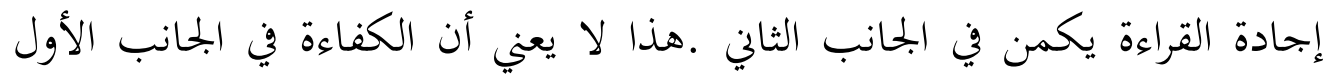

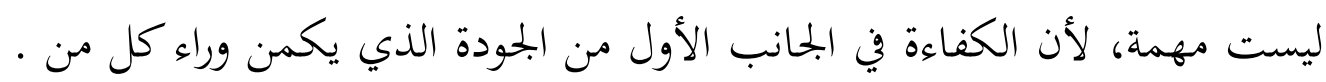
بعد كل شي، وكلاهما الأهداف التي ينبني تحقيقها في تعليم اللغة. مهارات القراءة أنشطة التعليم بالمعنى الأول منحت منذ بداية المستوى،

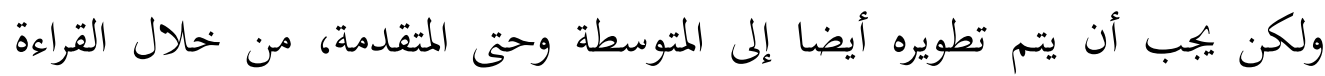
بصوت عال سورة آلخهرية أوقراءة في الكبد.

\section{1. إتقان كتابة اصبح رمز تغيير تأثيرات صوتية}

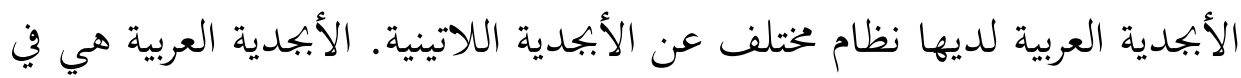

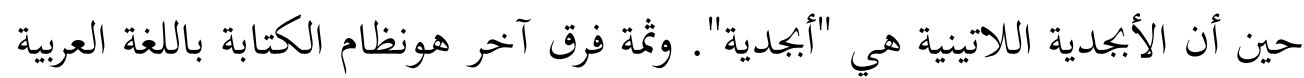

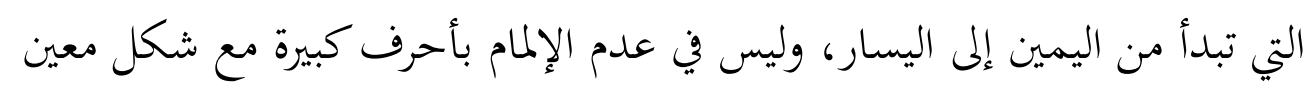

${ }^{9}$ Ibid, hlm. 168-172. 
لبدء سطر جديد، وكتابة أسماء الأشخاص أوالأماكن، وأشكال مختلفة من الحروف العربية عند الوقوف وحدها، في بداية ووسط وفي هاية المطاف.

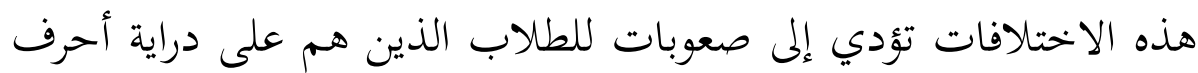
لاتينية بالفعل .إلى جانب حقيقة أن كتب اللغة العربية مثل المجلات والصحف تكتب بدون استخدام علامات حرف العلة خطوط .على الرغم من أن خط هوعلامات حرف العلة التي تحدد معنى وظيفة الكلمة في الجملة. Y . فهم معنى قراءة إتقان

هناك ثلاثة عناصر يجب النظر فيها وتطويرها في تعلم القراءة عناصر من الكلمات والجمل والفقرات .عندما تكون هذه العناصر معا لدعم معنى مادة القراءة .الكلمات محتمعة تشكل أكبر وحدة تسمى الجملة، وتشكيل أكبر وحدات تسمى فقرات وفقرات واحدة تتكون من فصول، ثم فصول تتألف كان كتاب.

$$
\text { و. أنواع من القراءة }
$$

لتدريب الجانب مهارة هناك نوعا من القراءة ويتم ذلك عادة من قبل شخص ما،

$$
\text { من بين أمور أخرى: }
$$

أ. القرأة الثابتة (القراءة الجهرية)

في قراءة هؤلاء المتطرفين، والتي شددت أساسا هوالقدرة على قراءة مع الحفاظ على الصوت دقة اللغة العربية، سواء من حيث فضلا عن خصائص الصوت من جهة أخرى، في إيقاع الكمال والعبارات التي تصف مشاعر الكاتب، وأيضا لا وقف تهن وتتكرر مرة أخرى، وإيلاء الاهتمام لعلامات الترقيم (علامة الترقيم). ب. القراءة في الكبد (القراءة الصامتة) 
قراءة بصمت تدف إلى اكتساب فهم، وكان كل من التفاصيل والتفاصيل. وبالتالي،

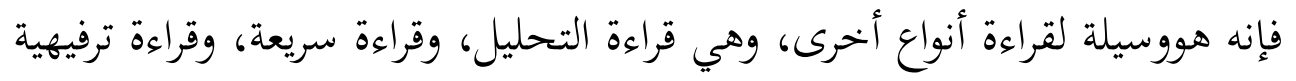

\section{ج. قراءة سريعة (القراءة السريعة)}

الهدف الرئيسي هوتشجيع الطلاب القراءة السريع ليجرؤ على قراءة العراء

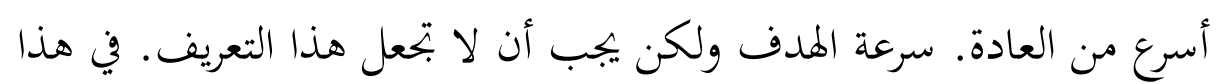

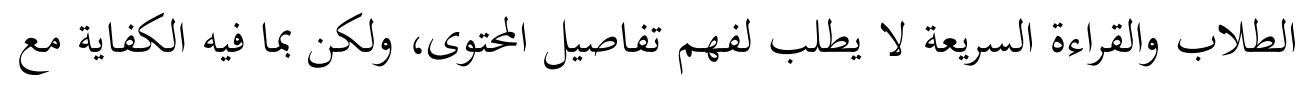

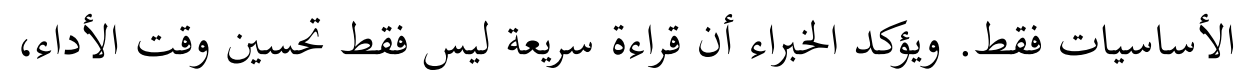

$$
\text { ولكن زيادة كمية المعلومات التي يمكن استيعاجما من قبل القارئ. }
$$

د. القراءة (القراءة الاستمتاعية)

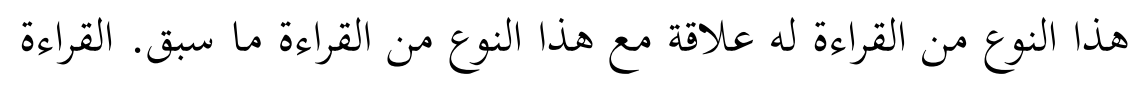

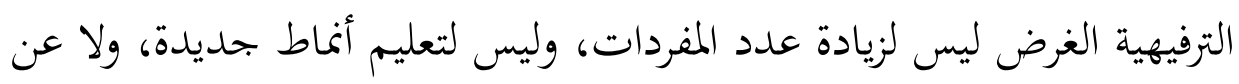

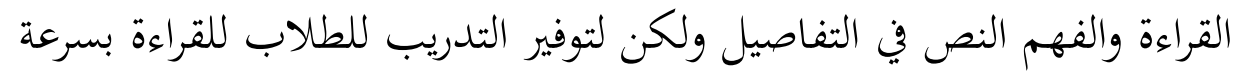

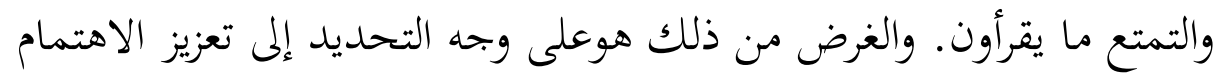

والحب من القراءة.

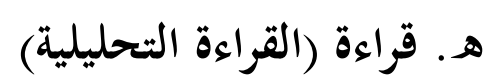

ان الهدق الاساسي من قراءة التحليلية هوتدريب الطلاب لديها القدرة

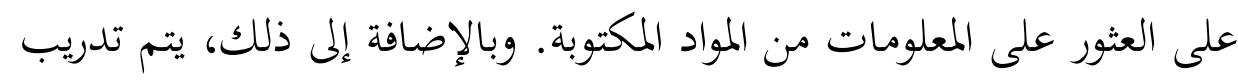

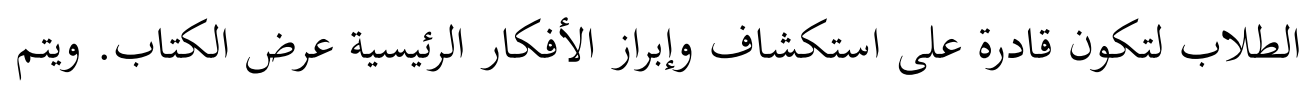

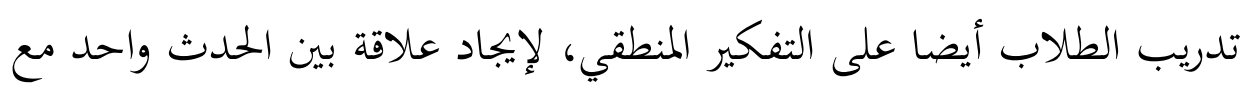


غيرها من الأحداث، واستخلاص النتائج، بالرغم من عدم ذكرها صراحة في الممر.

ز. تعريف اللغةالعربية

اللغة هي الكلمات التي وصفت له كل الأمة (الشعب) من هذا الغرض.

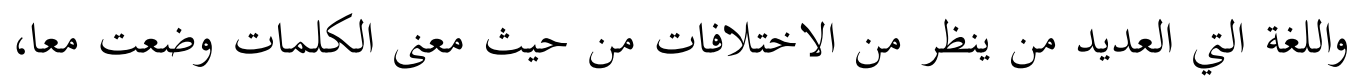

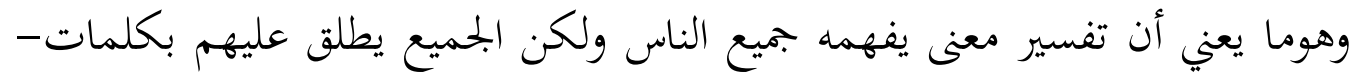

الكلمات التي تختلف. 10

في حين أن الجملة العربية الذي يطلق عليه العرب من صالحهم. اللغة في

قاموس الإندونيسية هي التعسفي نظام رمز الصوت، الذي يستخدم من قبل أفراد من

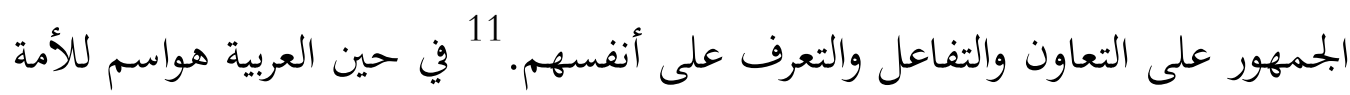

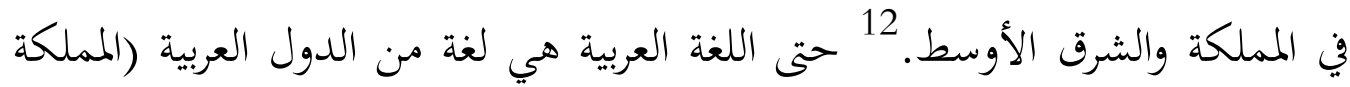
العربية السعودية، سوريا، الأردن، العراق، مصر، وهلم جرا).

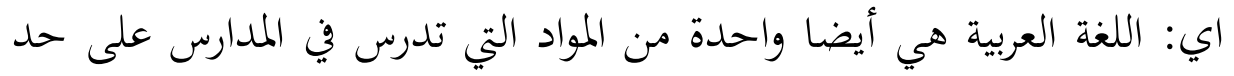

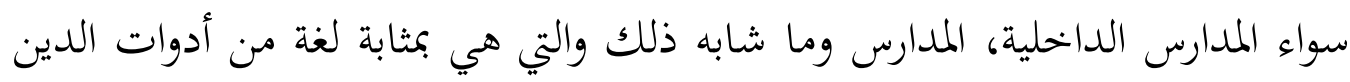

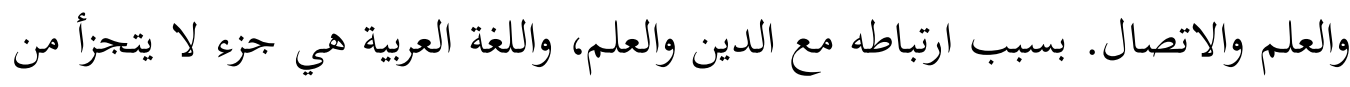

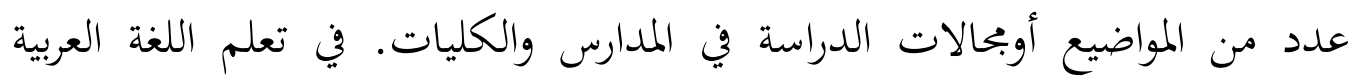
تمدف إلى تطوير المهارات اللغوية على حد سواء شفويا وخطيا. مع المهارات الشفهية، يتوقع من الطلبة لإتقان عدد من المفردات وتركيب الجمل، ويمكن الحديث المديث

\footnotetext{
${ }^{10}$ Ahmad Musthafa al-Golayani, Jamik ad Durus al-Arabiyah juz 1 Maktabah al- Suruh al-Dauliyah (Libanon: 2008), hlm. 3

${ }^{11}$ Departemen Pendidikan dan Kebudayaan RI. Kamus Bahasa Indonesia, (Jakarta: Balai pustaka, 1995), hlm. 312

${ }^{12} \mathrm{Ibid},$. hlm. 62
} 
بنشاط مع من المتوقع أن قراءة وفهم ومناقشة النص العربي الطلاب مهارات الكتابة، وخاصة تلك التي ترتبط بشكل وثيق مع الإسلام. 13

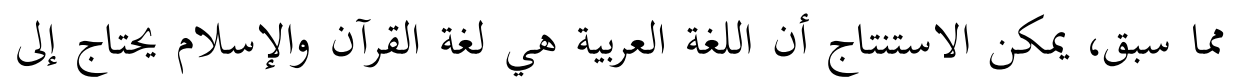

$$
\begin{aligned}
& \text { معرفة اللغة العربية لتعاليم الإسلام يرتبط ارتباطا وثيقا العربية. } \\
& \text { اللغة العربية أسلوب التعلم }
\end{aligned}
$$

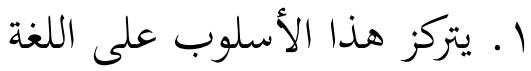

$$
\begin{aligned}
& \text { أ. طريقة لقواعد اللغة ترجمة } \\
& \text { ب. - ب الطريقة المباشرة } \\
& \text { ج. طريقة القراءة } \\
& \text { د. طريقة الصوت اللغات }
\end{aligned}
$$

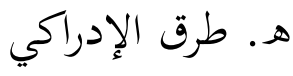

$$
\begin{aligned}
& \text { و. أسلوب انتقائي } \\
& \text { r أ. وتتركز هذه الطريقة على التعلم } \\
& \text { أ. طريقة من الكل } \\
& \text { ب. طرق الطريق الصامت } \\
& \text { ج. ل طرق الإرشاد الدراسة } \\
& \text { د. الأساليب الطبيعية }
\end{aligned}
$$

\section{ب. خطوات تعلم اللغة العربية}

اي: في وضع الخطوات لتعلم اللغة العربية، ثم يجب علينا أن نعرف الأهداف

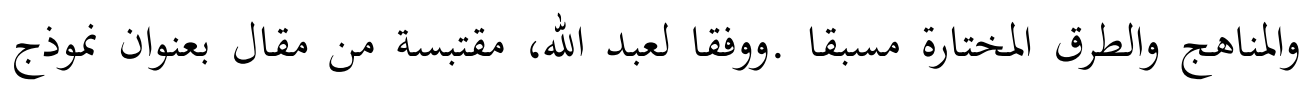

\footnotetext{
${ }^{13}$ Faisal Hendra dkk, Kemampuan Berbahasa Arab, (Jakarta: Gaung persada Press, 2007), hlm. 1
} 
تعلم اللغة العربية في كلية الدين الإسلامي من الخاصة، يعتبر الغرض من تعلم اللغة العربية واقعية وملموسة هوفهم المادة التي يتم التعبير في اللغة العربية من قبل هيكل

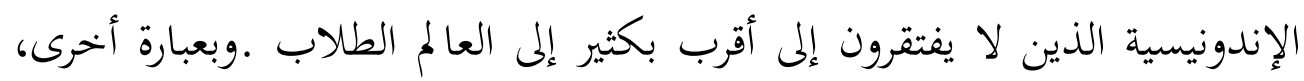
وتطوير القدرة على تحليل بنية المهارات اللغوية والبحث العربية تعادل في الإندونيسية. استنادا إلى الأهداف المذكورة أعلاه تعتبر النهج ذات الصلة لتعلم اللغة العربية هي كانت النهج والنهج الهيكلية والنحوية ناجحة إذا لم يتحقق ذلك في تدابير ملموسة ـوفقا للنهج المختار، وأساليب تدريس اللغة العربية يعتبر مؤقتا أساليب مناسبة وفعالة من قواعد اللغة وطريقة, آلقواعد روا آلترجمة. الخطوات التي يمكن اتخاذها في تعلم اللغة العربية مع هذه الطريقة هي كما

أ. تحديد وصياغة الأهداف التعليمية في واضحة وملموسة، والوظيفية. ب. تصميم وتخصيص المواد التي سيتم تطويرها من خلال الممارسة تشريح بنية اللغة،

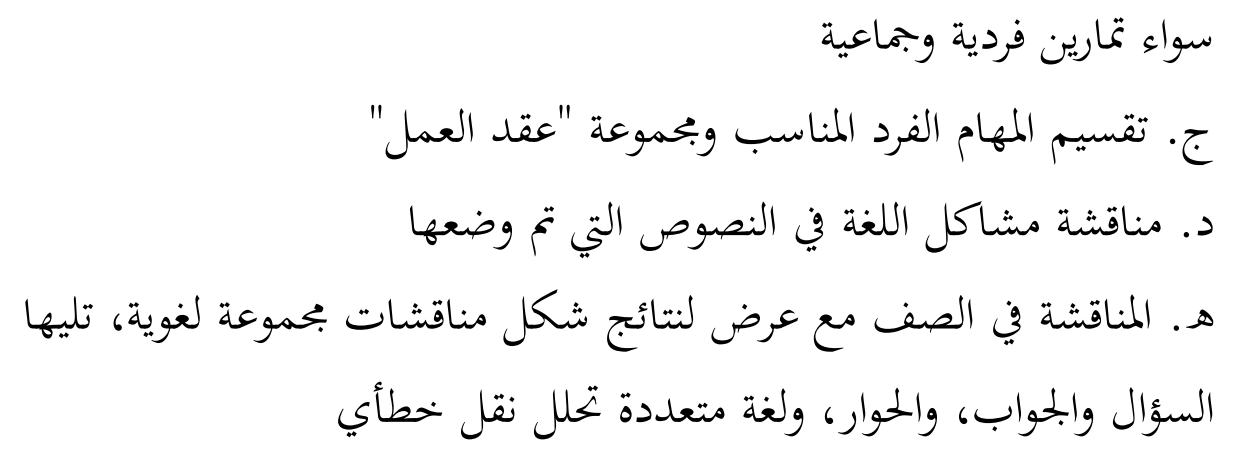

${ }^{14} \mathrm{Http} / /$ : //blogspot.Com/2016/12 Diakses 5 Desember 2016 Pukul 17.00 WIB 


\section{ع ـ تعلم المهارة اللغوية}

للغةأربعة مهارات, هي : الاستماع، الكلام، القراءة، والكتابة. والوسيلة التي تنقل مهارة الكالام هي الصوت عبر الاتصال المباشرين المتكلم والمستمع. أما مهارتا القراءة والكتابة، فوسيلتهما الحرف المكتوب. 15

ويتحقق الاتصال بالمهارتين الأخبرين، دون قيود الزمان والمكان. ومن ناحية أخرى يتلق الإنسان المعلومات والخبرات، عبر مهارتي الاستماع والقراءة، فهما مهارة استقبال، ويقوم الإنسان عبر مهارتي الكلام والكتابة ببث رسالته، بما تحويه من معلومات وخبرات، فهما مهارتا إنتاج.

\section{الخلاصة}

هذا الفصل هواهيار من الأسئلة الأساسية لمذا البحث من قبل المؤلفين، كما يلي: 1. توضح عملية تعلم اللغة العربية في الصف الثامن العديد من المشاكل الناجمة لا تزال العديد من الطلاب الذين ما زالوا لا يفهمون أساليب المحتوى والأساليب المادية تدرس ماستر.

r.مشاكل الطلاب في تعلم المهرة القراءمدرسة المتوسطة الاسلامية الحكومية الاولى نموذج بادانج سيدمبوان هوعدم وجود البنية التحتية التيتملكها من قبل المدرسة، وبالتالي فإن الأسرة والبحتمع والمعلمين الأكثر نفوذا وأولياء الأمور بسبب التدقيق والاهتمام أن تحصل متحمس وطلاب تخصص لا شيء هي الصعوبات التي تواجهرها عند تعلم تأخذ مكان. 


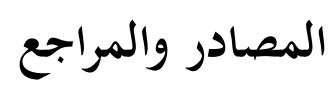

Eveline siregar dan Hartini Nara, Teori Belajar dan Pembelajaran, Bogor: Ghalia Indonesia, 2010

Tim Penyusun Departemen Pendidikan Dan Kebudayaan, Kamus Besar Indonesia, Jakarta: Balai Pustaka, 1991

Oemar Hamalik, Kurikulum dan Pembelajaran, Jakarta: Bumi Aksara, 2008 Depag, Undang-Undang dan Pemerintahan RI Tentang Pendidikan, Jakarta: Dirjen Pendidikan Islam Departemen Agama RI, 2006.

Tohirin,Psikologi Pembelajaran Pendidikan Agama Islam, Jakarta:PT.Raja Grapindo Persada, 2005

Oemar Hamalik, Kurikulum dan Pembelajaran, Jakarta: Bumi Aksara, 2008

Syaiful Mustofa, Strategi Pembelajaran Bahasa Arab Inovatif, UIN MALIKI PRESS, 2011

Ahmad Musthafa al-Golayani, Jamik ad Durus al-Arabiyah juz 1 Maktabah alSuruh al-Dauliyah, Libanon: 2008

Departemen Pendidikan dan Kebudayaan RI. Kamus Bahasa Indonesia, Jakarta: Balai pustaka, 1995

Faisal Hendra dkk, Kemampuan Berbahasa Arab, Jakarta: Gaung persada Press, 2007

Http//: //blogspot.Com/2016/12 Diakses 5 Desember 2016 Pukul 17.00 WIB 